\title{
RETRACTED ARTICLE: Experimental and theoretical study of functionalized diterpenoids of salvinorin A type and molecular factors contributing to their selectivity to $\kappa$-opioid receptors
}

\author{
Bojidarka Ivanova $\cdot$ Michael Spiteller
}

Received: 19 February 2013/Accepted: 22 October 2013/Published online: 7 November 2013

(c) Springer Science+Business Media New York 2013

This article has been retracted due to inconsistencies between the reported compounds and the NMR experimental data.

B. Ivanova $(\bowtie) \cdot$ M. Spiteller Lehrstuhl für Analytische Chemie, Institut für Umweltforschung, Fakultät für Chemie, Universität Dortmund, Otto-Hahn-Straße 6, 44227 Dortmund, North Rhine-Westphalia, Germany

e-mail: b.ivanova@infu.uni-dortmund.de; b.ivanova@web.de 